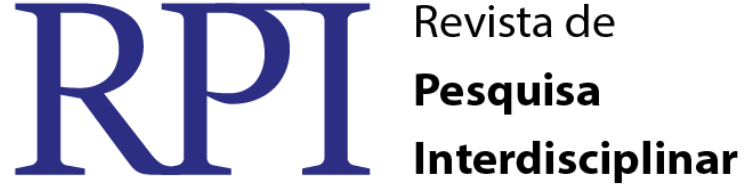

\section{PROJETO INTERDISCIPLINAR NA EXECUÇÃO DO ESTÁGIO CURRICULAR SUPERVISIONADO DE ENSINO EM GEOGRAFIA IV}

\author{
Jucier Ricarte Saraiva - UFCG ${ }^{1}$ \\ Laurindo Francisco Duarte Filho - UFCG ${ }^{2}$ \\ Maria da Glória Vieira Anselmo - UFCG ${ }^{3}$
}

\begin{abstract}
Resumo
Este trabalho tem como finalidade é realizar a regência interdisciplinar e na disciplina de estágio durante todo o curso de licenciatura em Geografia pela UFCG. O referido estágio supervisionado tem uma carga horária de 120 horas, como está posto no PPC do curso. O Estágio Supervisionado é um elemento curricular obrigatório para todos os alunos do Curso de Geografia. Essa pesquisa busca relacionar os conhecimentos teóricos adquiridos na academia com as percepções da realidade escolar, trabalhando os conteúdos de forma interdisciplinar, aprimorando mais ainda as qualidades do professor em formação. Analisa também o processo de formação do educando de forma interdisciplinar, pois essa metodologia vem sendo muito discutido na contemporaneidade, e isso vem modificando a maneira de ensinar, com foco em transformar essa realidade que vemos diariamente. $\mathrm{O}$ Estágio tem como foco fundamental o contato entre os estagiários (a) com a realidade educacional no nível do ensino fundamental e Médio, o qual está em questão. O estágio não é apenas o momento de aplicação do que foi assimilado, mas sim a explicitação da indissociabilidade entre a teoria e a prática e seus elementos que os compõem. A fim de atingir os objetivos foram feitas observações e realização de questionário com alunos e professores. Conclui-se que os alunos da sala escolhida para a regência tem uma relação harmoniosa com todos da gestão escolar e professores.
\end{abstract}

Palavras-chave: Interdisciplinaridade; Estágio; Docência; Ensino.

\section{INTERDISCIPLINARY PROJECT IN THE IMPLEMENTATION OF THE SUPERVISED CURRICULAR STAGE OF EDUCATION IN GEOGRAPHY IV}

\begin{abstract}
This work aims to explain the activities carried out in the stage of discipline throughout the course of degree in Geography from UFCG. Said supervised has a workload of 120 hours, as it is put in the PPC course. The Supervised Internship is a compulsory curriculum element for all students of the Geography Course. This research seeks to relate the theoretical knowledge acquired in the gym with perceptions of school reality, working in an interdisciplinary way the content, further enhancing the teacher's qualities in training. It also analyzes the process of formation of the student in an interdisciplinary way, as this methodology has been much discussed in contemporary times, and this is changing the way of teaching, with a focus on transforming this reality that we see daily. Stage is fundamentally focused on the contact between the trainees (a) with the educational reality at the level

\footnotetext{
${ }^{1}$ Universidade Federal de Campina Grande - Campus de Cajazeiras/PB. jucierricarte@ hotmail.com

${ }^{2}$ Universidade Federal de Campina Grande - Campus de Cajazeiras/PB. laurindoduarte9@gmail.com

${ }^{3}$ Docente do Curso de Licenciatura Plena em Geografia da UFCG/CFP- Cajazeiras, Paraíba. Gloria.anselmo@ hotmail.com
} 
of elementary school and high school, which is in question. The stage is not only the time of application of what has been assimilated, but the explanation of the inseparability of theory and practice and its component parts.

Keywords: interdisciplinarity; Internship; teaching; Teaching.

\section{INTRODUÇÃO}

O principal foco deste projeto é trabalhar com uma área distinta da Geografia de forma que ambas seja enfatizadas na regência do Estágio Curricular Supervisionado de Ensino em Geografia IV, proposto assim pela professora da própria disciplina para assim concluir o Estágio.

O assunto lecionado na regência será o capitalismo na industrialização de forma que consigamos mostrar de forma coesa os dois lados da história do conteúdo, e não mostrar o lado a que convêm explicitar, fazendo com que assim os alunos possam refletir qual delas melhor lhe convenceu.

A realização do Estágio Curricular Supervisionado de Ensino em Geografia IV irá ser realizado na Escola Estadual de ensino Fundamental e Médio Monsenhor Constantino Vieira, que é conhecida popularmente como Colégio Comercial de Cajazeiras ou Escola Técnica, localizado na Rua Padre Rolim, 457, em Cajazeiras - PB.

Para a execução deste projeto fez-se necessário à leitura de uma vasta literatura sobre Plano Nacional de Educação (PNE), Base Nacional Curricular Comum, formação docente, interdisciplinaridade, Práxis, Estágio Supervisionado, avalição, historiografia da escola, assim como observações no colégio a fim de elaborar um projeto que se encaixasse nos moldes da escola objeto de pesquisa.

O objetivo desta pesquisa é relacionar os conhecimentos teóricos adquiridos na academia com as percepções da realidade escolar, trabalhando os conteúdos de forma interdisciplinar, aprimorando mais ainda as qualidades do professor em formação.

Para alcançar tais objetivos foram realizadas visitas na Escola Estadual de ensino Fundamental e Médio Monsenhor Constantino Vieira, onde fez-se algumas observações durantes aulas em sala, para observar, coletar informações sobre a escola e alunos, teve-se a

RPI Revista de Pesquisa Interdisciplinar, Cajazeiras, v. 1, Ed. Especial, 412 - 429, set/dez. de 2016. 
aplicação de questionários com os alunos, com a finalidade de compreender como está a relação deste com os docente da escola.

\section{Formação Docente, Estágio Supervisionado E Práxis}

O Estágio Curricular Supervisionado de Ensino em Geografia IV está acontecendo na Universidade Federal de Campina Grande (Campos Cajazeiras- PB), onde foi transcorrido debates de textos referentes aos documentos oficiais do Ensino Médio, da Educação Nacional e como do próprio Curso de Licenciatura em Geografia. Durante esse trajeto foi realizado o contrato entre Ensino Básico e Superior, assim como também da ponte de conhecimento para ambos (Ensino Básico e Superior), teve-se ainda o planejamento com a professora de Estágio, sobre o que seria realizado na disciplina, onde foi proposta a interdisciplinaridade.

A parte do Estagio Supervisionado torna-se a fase crucial para a adequada formação do profissional de educação, pois, é o momento que este pode mostrar e por em prática todo seu conhecimento teórico metodológico, e assim possa este mesmo medir o seu desempenho em sala, através de um olhar critico reflexivo capaz de identificar acerto e possíveis erros, isso vai de encontro ao afirma Barbosa e Amaral (2009, pg. 3678):

O estágio proporciona ao educando adotar um olhar de educador em relação àsquestões do exercício da profissão. Para a realização desse estudo foi solicitado que os alunosdo curso de Pedagogia respondessem sobre as maiores dificuldades enfrentadas durante a realização do estágio supervisionado.

Nesta perspectiva de Barbosa e Amaral afirma acima que a realização do Estágio Supervisionado faz com que o discente amadureça suas concepções metodológicas para a prática futura, no qual este se preparou durante toda a graduação, esta linha de raciocínio vai de encontro com a afirmação de Saraiva (2015, pg. 7/8) concerne sobre Estágio supervisionado:

A disciplina de Estágio Supervisionado de Geografia I fez com que a turma refletisse sobre como se encontra o ensino de geografia hoje nas escolas municipais ou estaduais, fazendo que repesássemos qual tipo de professores queríamos ser no futuro e qual realidade desejávamos ter em nosso município, tornando assim nossa visão do que representa o Estágio mais aguçado e assim modificar a realidade do ensino de geografia das escolas seja do interior ou dos grandes centros [...].

RPI Revista de Pesquisa Interdisciplinar, Cajazeiras, v. 1, Ed. Especial, 412 - 429, set/dez. de 2016. 
No entendimento de Saraiva o Estágio constitui assim a parte final do refinamento do profissional da educação e por uma realização feita de forma coesa e coerente a demanda da necessidade local pode elevar o nível educacional da rede básica de ensino das escolas locais.

A formação docente de cada profissional da educação passa pela conclusão realizada no Estágio Supervisionado de cada área do ensino, seja na Geografia, na História e demais, no qual a forma como transcorra essa realização pode se inserir no mundo educacional um profissional extremamente preparado ou não para exercer tal função, onde será notado na sua Práxis educacional.

Segundo Hypolitto (2009) os profissionais da educação no Brasil têm deficiência de embasamento teórico que é resultado da sua formação acadêmica, e os que se detém este requisito é por esforços privados do seu próprio capital, já para Pena apud Shulman(2011. Pg. 110) a formação docente tem outras dificuldades, como ele afirma abaixo:

De acordo com Viçosa apud Shulman (2005), no âmbito dos estudos sobre a aprendizagem da docência, existe uma base de conhecimento para o ensino que se refere a um repertório profissional. Este, por sua vez, contém categorias de conhecimento que subjazem à compreensão que o professor necessita para promover as aprendizagens dos alunos. Essa base de conhecimento está na capacidade do professor para transformar seu conhecimento do conteúdo em formas de atuação que sejam pedagogicamente eficazes para a aprendizagem dos alunos. Dentre as categorias dessa base de conhecimento, para o autor, é o conhecimento pedagógico do conteúdo que identifica um corpo de conhecimentos distintivos para o ensino. Ele representa uma amálgama entre matéria e didática, pela qual se chega a uma compreensão de como determinados temas ou problemas se organizam, se representam e se adaptam aos diversos interesses e capacidades dos alunos. É esse tipo de conhecimento que, segundo o autor, permite distinguir entre a compreensão do especialista em uma área de saber e a compreensão do educador.

Já outros pesquisadores afirmam que as formações destes profissionais devem ser enxergada por outro viés, onde cada um destes individuos tem de buscar sua reformação profissional após concluírem seus respectivos cursos, onde Nunes (2001, pg. 30) reforça essa ideologia teórica abaixo.

Dessa forma, resgata a importância de se considerar o professor em sua própria formação, num processo de autoformarão, de reelaboração dos saberes iniciais em confronto com sua prática vivenciada. Assim seus saberes vão-se constituindo a partir de uma reflexão na e sobre a prática.

RPI Revista de Pesquisa Interdisciplinar, Cajazeiras, v. 1, Ed. Especial, 412 - 429, set/dez. de 2016. 
Essa tendência reflexiva vem-se apresentando como um novo paradigma na formação de professores, sedimentando uma política de desenvolvimento pessoal e profissional dos professores e das instituições escolares.

Nessa citação do trabalho de Nunes (2001) percebe-se claramente que a deficiência da formação inicial dos profissionais da educação e que estes devem buscar além da sua formação primaria outro saberes e conhecimento teórico, seja de fonte privada ou pública.

Essa teoria que o professor deve estar sempre procurando melhorar e aperfeiçoar metodologicamente como aprofundamento do conhecimento especifico da sua área é ressaltado também por Dassoler e Lima (2012, pg. 2)

O professor é um profissional que domina a arte de reencantar, de despertar nas pessoas a capacidade de engajar-se e mudar. Neste aspecto, entende-se que a formação do professor é indispensável para a prática educativa, a qual se constitui o lócus de sua profissionalização cotidiana no cenário escolar. Desse modo, compreender a formação docente incide na reflexão fundamental de que ser professor é ser um profissional da educação que trabalha com pessoas. Essa percepção induz este profissional de educação a um processo permanente de formação, na busca constante do conhecimento por meio dos processos que dão suporte à sua prática pedagógica e social. Neste sentido, a educação é um processo de humanização e, como afirma Pimenta (2010), é um processo pela qual os seres humanos são inseridos na sociedade.

A concepção de Dassoler e Lima cita acima se enquadra em adequância ao que este trabalho almeja que é justamente transpor a barreira e dificuldades encontradas na realização deste projeto, assim como também se objetiva motivar e "fabular" o caminho do conhecimento para que os alunos busquem trilhar este caminho, seja este o da própria Geografia ou outro.

A Práxis é a fase final do profissional da educação que caracteriza o momento que este conclui sua formação e começar a percorrer o caminho do ensino na esfera básica da educação.

Segundo Berbel (2013) a Práxis é criadora de novas metodologias ou inovações de ensino e até mesmo estratégias de solução para a baixa aprendizagem dos alunos em sala de aula, assim como expõem a limitação de cada profissional.

Vazquez (1977) também concorda com Berbel, e afirma que a Práxis estar relacionada à mudança que um profissional com formação adequada mudar o entorno da escola, porém RPI Revista de Pesquisa Interdisciplinar, Cajazeiras, v. 1, Ed. Especial, 412 - 429, set/dez. de 2016. 
deve buscar ir além e ver que interesse a sociedade tem e assim traçar metodologia que transformem o lugar.

Já para Noronha (2005) a práxis é a relação o de trabalho com sua produção em que compreendi uma atividade social conscientemente dirigida a um objetivo, sendo assim a práxis, pode ser considerada uma categoria fundamental na transformação do meio natural

Estágio Supervisionado, Formação Docente e Práxis estão interligadas no percurso da educação, onde um erro em qual qualquer um deles pode inserir um profissional sem preparo. Fica explícito aqui neste trabalho que o Estágio é à base da Formação Docente e a Práxis a exposição desta base, em que todos estão interligados.

\section{Interdisciplinaridade}

Como já foi dito e sabemos da importância do Estágio na formação do professor. No Estágio Curricular Supervisionado de Ensino em Geografia IV foi proposto que fosse realizado de forma interdisciplinar, sendo assim uma maneira de fazer que o profissional da Geografia possa abranger ainda mais sua vasta área de analise e no futuro docente possa trabalhar de forma interdisciplinar e coletivamente nas instituições de ensino.

A interdisciplinaridade acontece quando duas áreas ou mais do conhecimento fazem uma ponte entre si a fim de facilitar o conhecimento de quem busca construir seus próprios conhecimentos (alunos). Silva (2012, pg. 5) também enxergar a interdisciplinaridade dessa forma, assim como expõem abaixo:

Por sua vez, a interdisciplinaridade, inicialmente concebida na ciência como a transferência de métodos de uma área para outra em três graus distintos; num grau de aplicação, num grau epistemológico e num grau de criação de novas disciplinas, ilustrados respectivamente pelos exemplos a seguir: no uso de métodos da física nuclear utilizados na medicina levando a novos tratamentos contra o câncer; na transferência de métodos da lógica formal para o campo do direito produzindo análises interessantes na epistemologia do direito e na transferência de métodos da química para a biologia, criando uma nova disciplina, a bioquímica (NICOLESCU, 2000), também começou a ser discutida, no contexto educacional, quando da formulação das questões de organização curricular e dos processos de ensino aprendizagem dos profissionais de educação.

RPI Revista de Pesquisa Interdisciplinar, Cajazeiras, v. 1, Ed. Especial, 412 - 429, set/dez. de 2016. 
Neste trecho Silva mostra como deve ocorrer à interdisciplinaridade e o que representa essa forma de trabalhar o conhecimento, nesta perspectiva será uma ferramenta essencial para a realização do Estágio IV, já que esta foi à forma proposta, assim como será mais um ganho técnico adquirido.

Esta concepção também é aceita por Hammes e Lomba (2009), onde afirma que o mundo compreende o conhecimento de forma espacializada e ressalva a necessidade de fazer a conexão entre as áreas do conhecimento e assim facilitar o entendimento de cada área para os alunos, pois, o explicar por explicar não acarreta ganho nenhum aos alunos.

Reche e Tuma (2013) compreendem de forma similar o que os autores anteriormente citados falar da realização do trabalho interdisciplinar, porém ressalva que além deste feito, ainda exige por parte dele dedicação, cooperação e mutua harmonia entre a equipe que propõem a trabalhar desta forma.

Dessa forma vemos que o trabalho interdisciplinar pode acarretar resultados positivo para ambos os lados (Ensino Básico e Superior/ Aluno do Ensino Básico e Superior), assim como também na compreensão da realidade das escolas e quais metodologia tem maior eficácia.

\section{Identificação Dos Sujeitos, Tema E Local Da Pesquisa}

A Escola escolhida para o Estágio Curricular Supervisionado de Ensino em Geografia IV foi a Escola Estadual de Ensino Fundamental e Médio Monsenhor Constantino Vieira, Onde segundo Antonio (2004) esta escola ficou conhecida popularmente como Colégio Comercial de Cajazeiras e Escola Técnica, localizado na Rua Padre Rolim, 457, em Cajazeiras - PB, situado na microrregião que leva o nome da própria cidade, estando inserido o colégio na mesorregião do Alto Sertão Paraibano.

Ainda segundo o mesmo esta escola foi criada no dia $1^{\circ}$ de dezembro de 1951 pelo prefeito Otacílio Jurema e Fundação Padre Ibiapina, onde o primeiro diretor desta instituição foi Doutor Manoel Ferreira de Andrade Júnior, porém durante muitos anos está escola foi de âmbito particular, e depois incorporada ao município de Cajazeiras-PB, e em seguida repassada ao Governo do Estado desde o período da gestão de Tarcísio Burity.

RPI Revista de Pesquisa Interdisciplinar, Cajazeiras, v. 1, Ed. Especial, 412 - 429, set/dez. de 2016. 
O mesmo ainda afirma tal instituição de Ensino já passou por inúmeras reformas, sendo feitas tanto pelo município como pelo Estado. O dinheiro investido nestas reformas já daria para construir mais três grandes escolas em Cajazeiras. Este Colégio até recentemente, era a escola com o maior número de alunos matriculados de Cajazeiras, em que pertencer ao CEPES. A vantagem desta escola é facilidade do deslocamento dos alunos pelo fato de se localizar no centro da cidade e por ter um nível de segurança do que o restante da cidade.

Para identificar melhor os alunos que vamos trabalhar neste projeto aplicamos um questionário para os professores e alunos, como também entender os interesses individuais dos mesmos.

Gráfico 1: Idade dos alunos, 2016. Gráfico 2: Estado civil dos alunos, 2016.

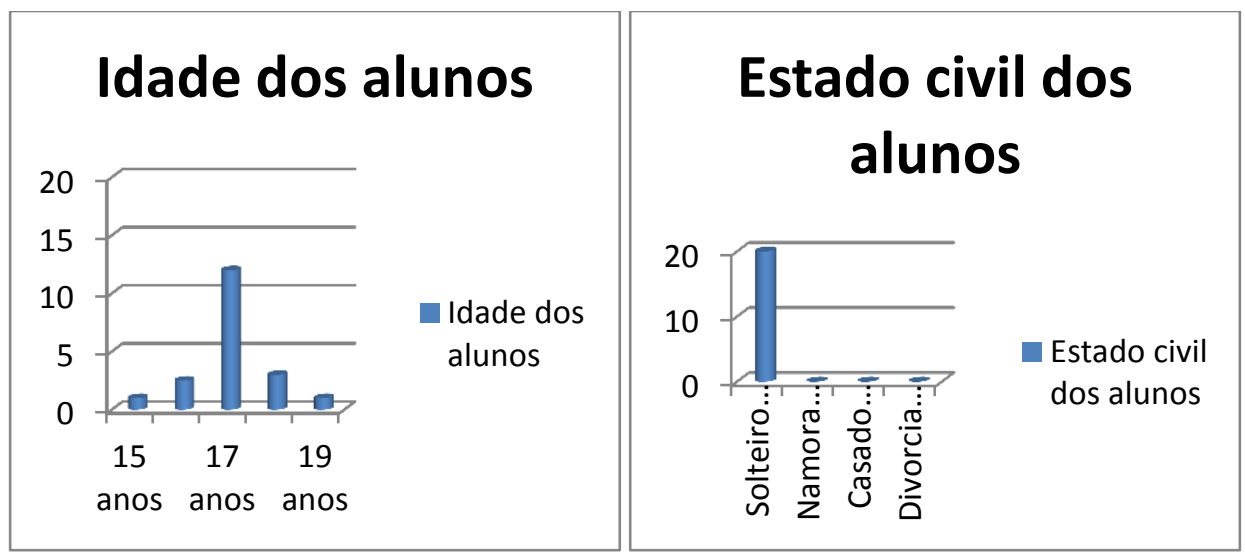

Fonte: Saraiva, Jucier Ricarte, Cajazeiras, Agosto de 2016.

A idade dos alunos desta turma segundo a pesquisa se apresenta dentro da idade certa, pois, cerca de $85 \%$ tem a faixa etária entre 15 e 17 anos, e outros $15 \%$ não chega há 20 anos, ou seja, é uma turma jovem e tem metas a serem alcançadas. A questão do estado civil do aluno tem influência direta no rendimento escolar pelo fato de sempre está preocupado com o bem estar da família, nesta turma não preocupação neste sentido pelo fato de todos serem solteiros como aponta o gráfico acima.

Gráfico 3: Quantos alunos exercem atividade remunerada, 2016. 


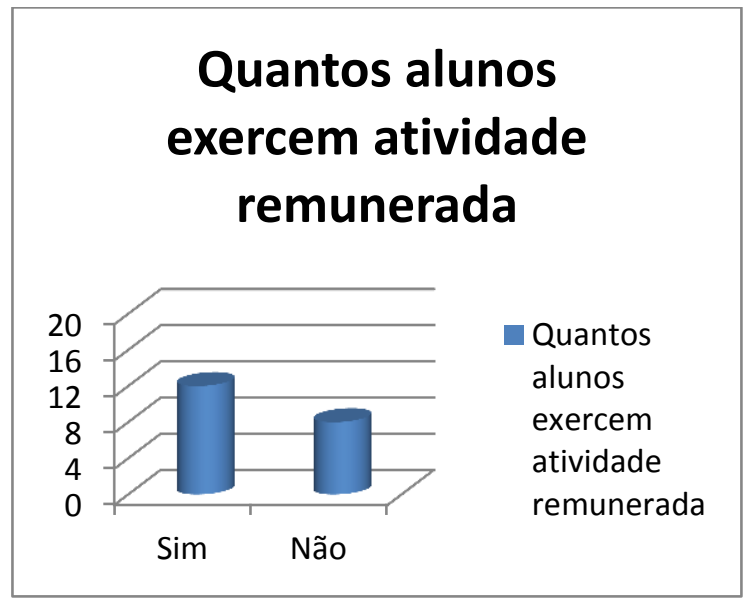

Fonte: Saraiva, Jucier Ricarte, Cajazeiras, Agosto de 2016.

Gráfico 4: Qual o motivo dos alunos terem escolhido o horário noturno, 2016.

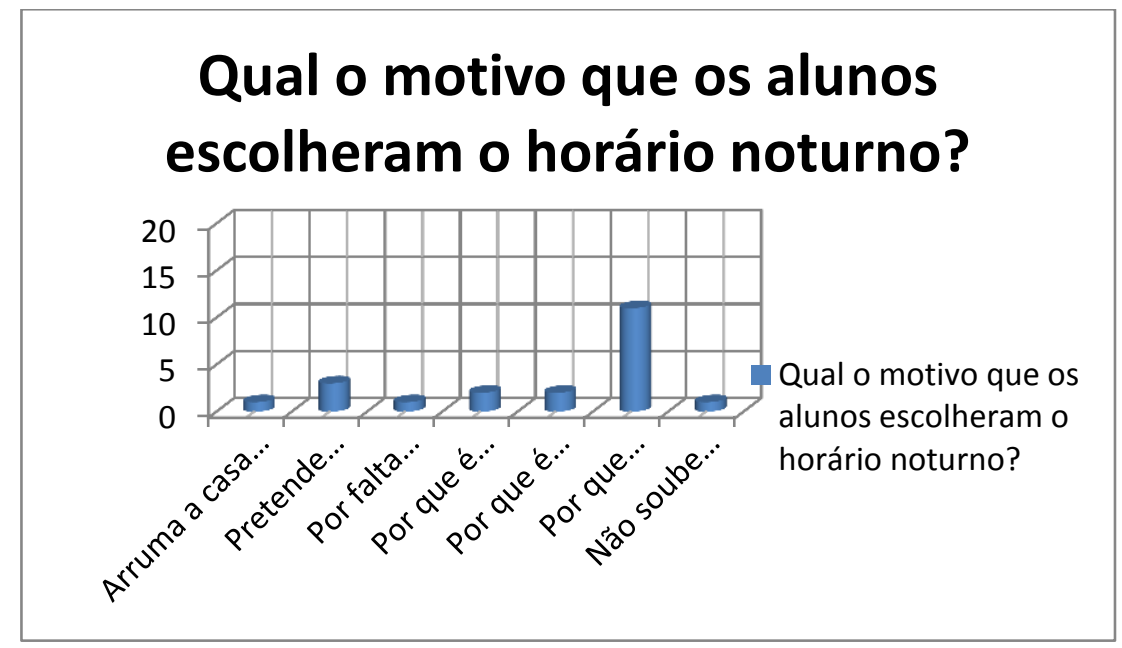

Fonte: Saraiva, Jucier Ricarte, Cajazeiras, Agosto de 2016.

A questão do trabalho pode sem um fator influenciador no desenvolvimento acadêmico dos alunos, já neste quesito a turma preocupa, pois, cerca de $60 \%$ da turma trabalha, porém, pode ser um ponto de equilíbrio pelo fato que desde cedo estes aprendem a lidar com a responsabilidade. A respeito da motivação dos alunos pela escolha dos alunos pelo horário noturno, e como no item anterior $60 \%$ afirmou trabalhar durante o dia e por este motivo escolheram este horário, e outros $40 \%$ se escolheram por ter pretensões de emprego ou serviços domésticos.

Gráfico 5: Quantos alunos pretendem ingressar no Ensino Superior e por quê, 2016.

RPI Revista de Pesquisa Interdisciplinar, Cajazeiras, v. 1, Ed. Especial, 412 - 429, set/dez. de 2016. 


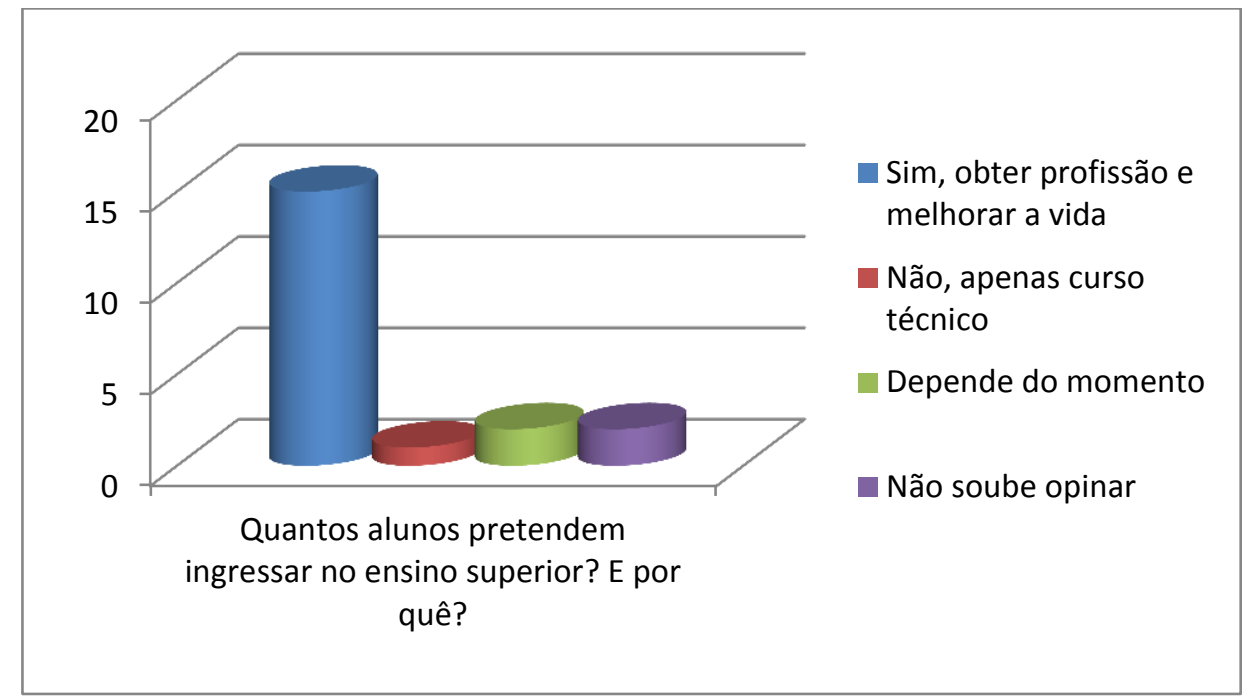

Fonte: Saraiva, Jucier Ricarte, Cajazeiras, Agosto de 2016.

Gráfico 6: Qual a relação dos alunos com os professore de História e Geografia, 2016.

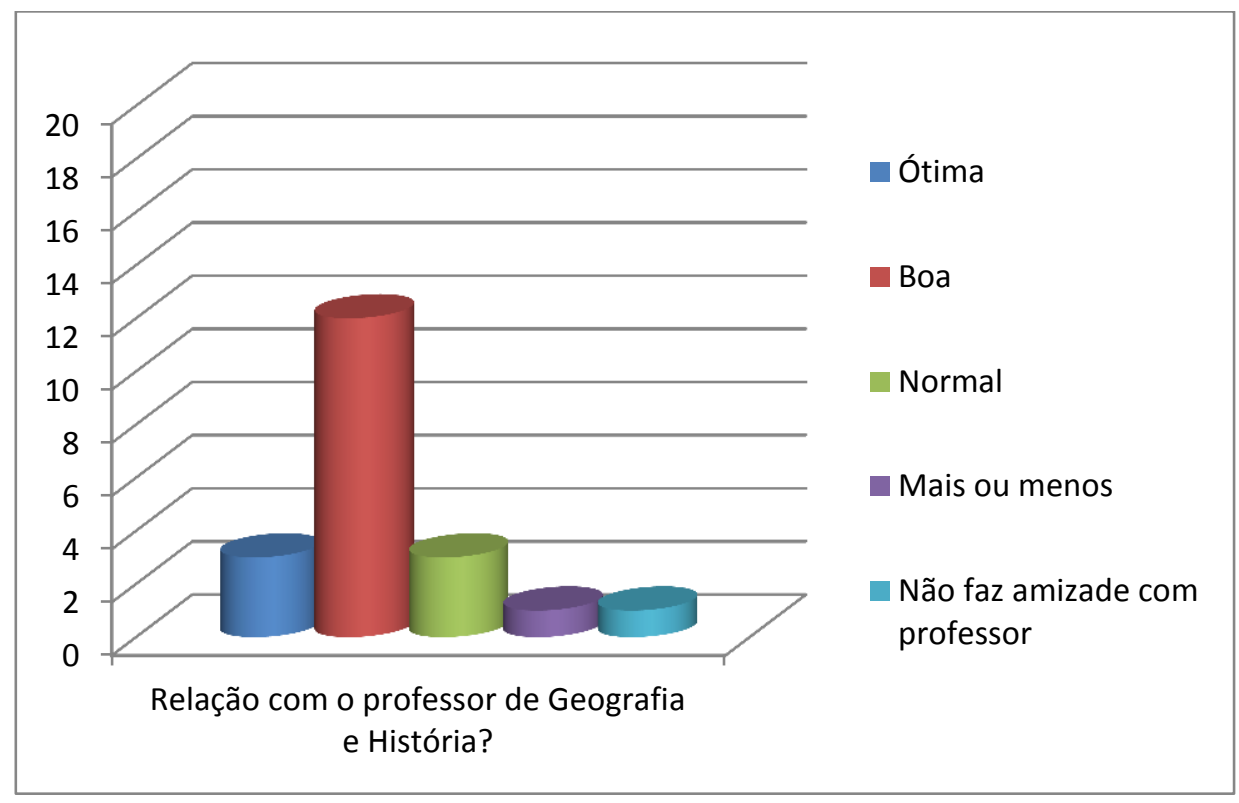

Fonte: Saraiva, Jucier Ricarte, Cajazeiras, Agosto de 2016.

Diante da preocupação com a turma pelo fato de $60 \%$ trabalharem durante o dia, pode se pensar que estes não pensem no futuro, mas na pesquisa $85 \%$ respondeu que pretende ingressar em curso superior e que dependo do seu momento de vida desejam adquirir uma profissão. A relação professor aluno apresenta bem nesta turma onde cerca de $80 \%$ afirmarem ter uma boa relação com os professores de História e Geografia, essa relação também se apresentou nas observações em sala de aula.

Gráfico 7: Sugestões dos alunos para melhorar as alunos de ambas as disciplinas, 2016.

RPI Revista de Pesquisa Interdisciplinar, Cajazeiras, v. 1, Ed. Especial, 412 - 429, set/dez. de 2016. 


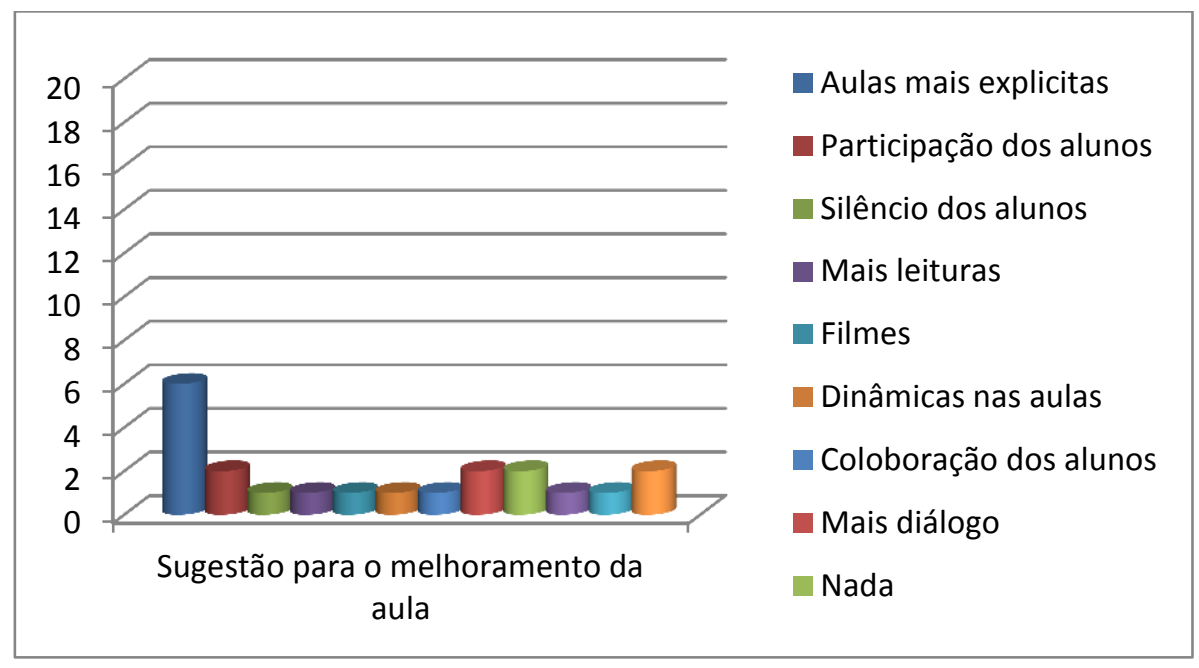

Fonte: Saraiva, Jucier Ricarte, Cajazeiras, Agosto de 2016.

Em relação ao que poderia ser melhorado na aula os alunos foram bastante sinceros e afirmaram que dependiam deles e citaram $75 \%$ das sugestões poderia ser feita por eles mesmos.

Gráfico 9: Ambos os professores trazem inovação as disciplinas, 2016.

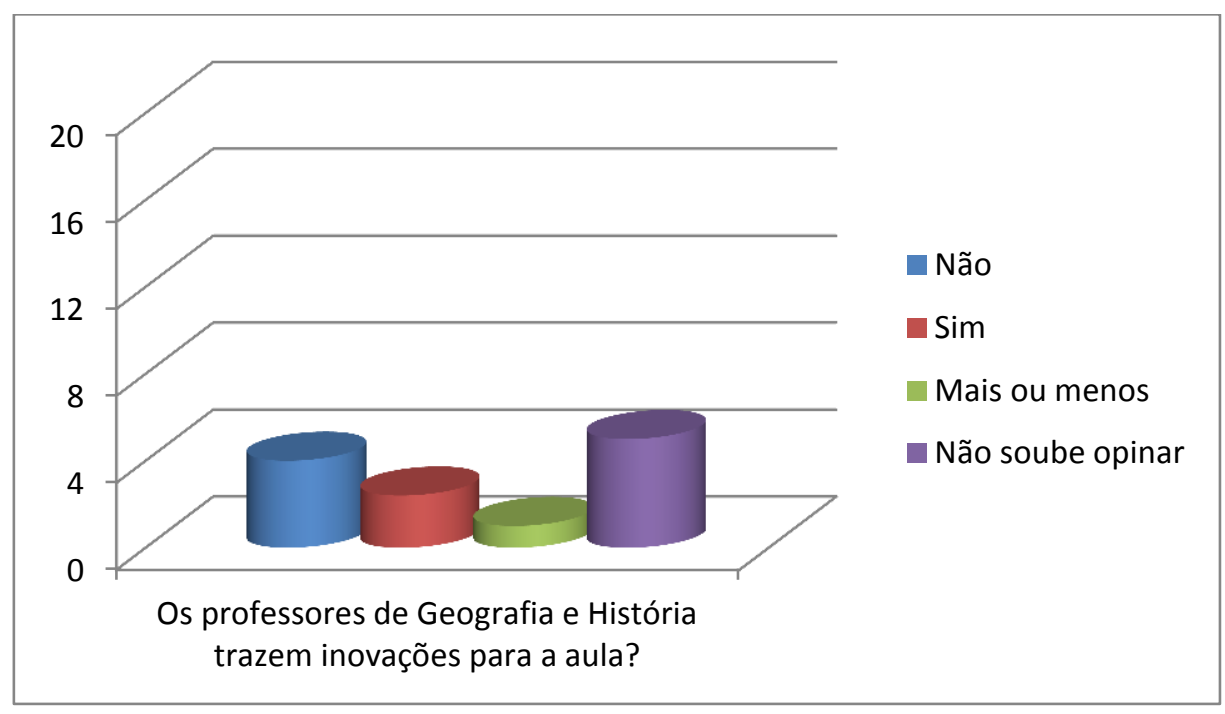

Fonte: Saraiva, Jucier Ricarte, Cajazeiras, Agosto de 2016.

Gráfico 10: Como os alunos classificam a sua relação com os professores de História e Geografia, 2016.

RPI Revista de Pesquisa Interdisciplinar, Cajazeiras, v. 1, Ed. Especial, 412 - 429, set/dez. de 2016. 


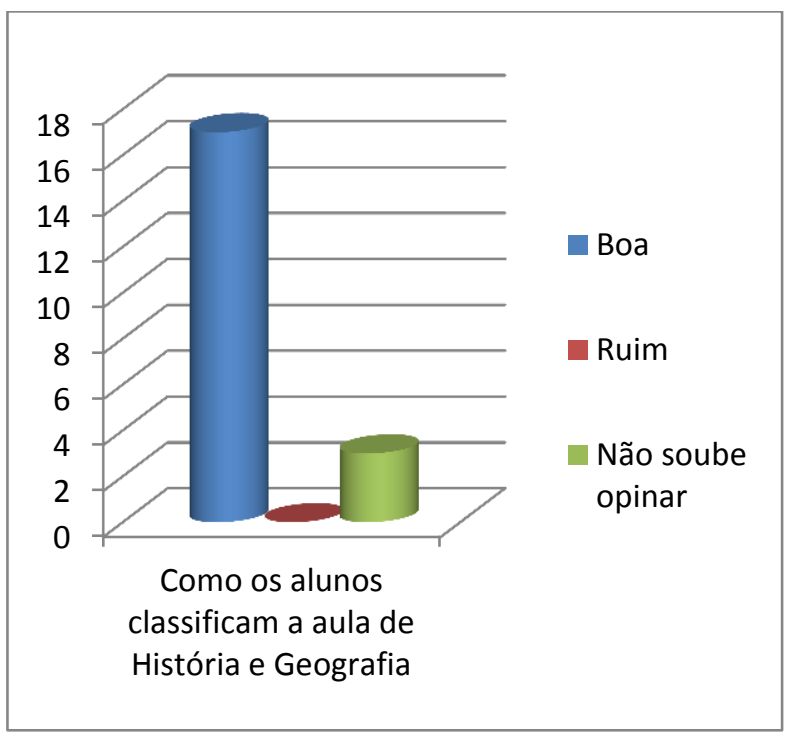

Fonte: Saraiva, Jucier Ricarte, Cajazeiras, Agosto de 2016.

A respeito da inovação que poderia ser trazidas pelos professores, os alunos ficaram bastante indecisos e a maior parte não soube responder, deixando um sinal de alerta ligado sobre como eles definem o que seria inovação. As aulas do professor de História como o de Geografia é conceituada pelos alunos em que chega a $80 \%$ de aprovação, no entanto o nível de alunos que não sabem chama a atenção chega próximo de $20 \%$.

Gráfico 11: O que os alunos acham que deveria ser melhorado, 2016.

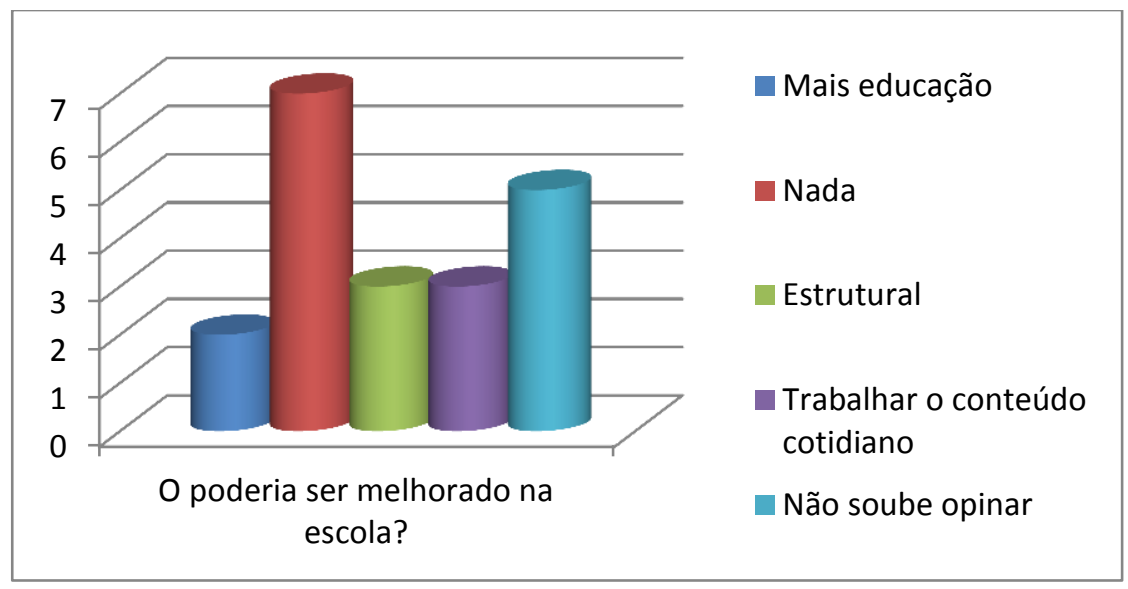

Fonte: Saraiva, Jucier Ricarte, Cajazeiras, Agosto de 2016.

Os itens citados pelos alunos que poderia ocorrer melhora ou mudanças é justamente estrutural, porém, a maior parte dos alunos coloram que o colégio se encontra em nível regular e que não necessitaria de mudanças, no entanto este majoritária divide o topo com os que não souberam opinar.

RPI Revista de Pesquisa Interdisciplinar, Cajazeiras, v. 1, Ed. Especial, 412 - 429, set/dez. de 2016. 
Gráfico 12: Quais oportunidade os alunos vêem na escola, 2016. Gráfico 13: Como os alunos avaliam seu próprio comportamento, 2016.
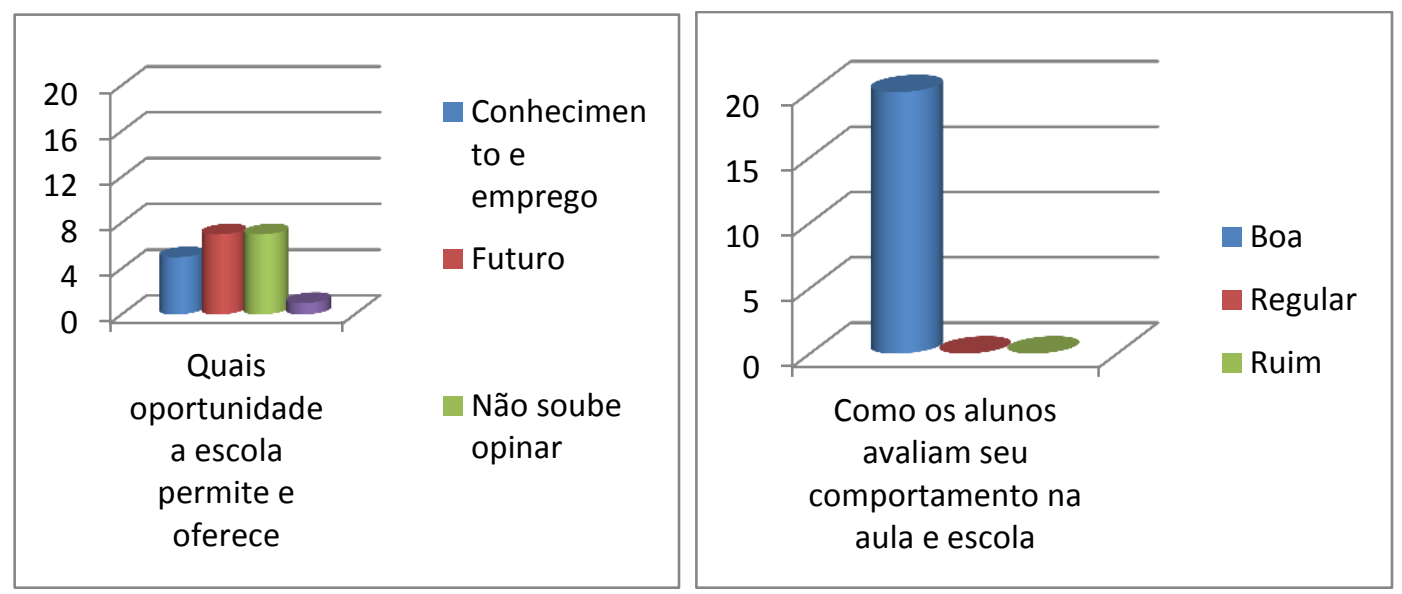

Fonte: Saraiva, Jucier Ricarte, Cajazeiras, Agosto de 2016.

Os alunos entendem que o caminho do conhecimento é o melhor e mais valioso para se mudar seu status social de vida, chega-se a esta conclusão pelo resultado do gráfico acima, onde $65 \%$ responderam que o conhecimento oferece oportunidades e transformar a parte social e mental da sua vida. No entanto um item que chama atenção é o alto índice de alunos que não souberam opinar, no qual chegou a $35 \%$. Nota-se que a auto avaliação dos alunos em relação ao comportamento tanto em sala de aula como na escola como um todo procede da mais alta conduta disciplinar, sendo conclui que o rendimento deste deva ser elevado.

Já no questionário dos professores quando perguntado Qual é a sua idade e a quantos anos você atua como educador, o professor de história ter 31 anos de idade e leciona a 10, já o professor de Geografia tem 60 anos de idade e 30 anos de sala de aula, poderia se pensar que idade o professor de Geografia estaria cansado, porém, nas aulas apresentou um profissional com disposição e interessado em fazer um bom trabalho. Quando indagados sobre quais as maiores dificuldades que você enfrenta no seu trabalho diariamente ambos responderam o interesse dos alunos.

Quando questionados referente ao que escola oferece suporte para que o seu trabalho seja mais eficiente, os dois disseram que disponibiliza todos os recursos solicitados por eles. Já quanto àrelação deles com as suas turmas responderam ser ótima. Ao ser perguntado se construiriam relações extra sala com seus alunos ou você vê isso como desnecessário, afirmaram quer são amigos dos alunos. Quanto à questão de como eles avaliam a sua importância na formação do cidadão colocaram que o profissional da educação tem papel central na formação cidadã.

RPI Revista de Pesquisa Interdisciplinar, Cajazeiras, v. 1, Ed. Especial, 412 - 429, set/dez. de 2016. 
No questionamento quanto a quem elabora o horário de aulas da escolae o que você acha do rendimento da sua disciplina com esse horário ouse conheciam os critérios para a elaboração, ambos os professores se opuseram ao horário formatado para as disciplina assim como a carga horaria. Quando se concordavam com a diminuição da carga horária os dois discordaram. Já quanto à opinião deles sobre a importância da sua disciplina para a vida dos seus alunos, afirmaram ser essencial para conhecer o passado, analisar o presente e planejar o futuro.

Ao serem questionado se trabalhavamsó nesta escola e Por que, o professor de História afirmou que não, pois, financeiramente era inviável, já o de Geografia afirmou que sim, trabalha apenas em uma escola. Quando perguntado se a escola teria alguma ação visando à aproximação dos pais do aluno e Quais, ambos afirmaram que sim, sendo este as reuniões de pais e mestre e projeto família e escola.

Já ao serem questionado se eles conseguiam enxergar problemas enfrentados por seus alunos que comprometam ou atrapalhem no aprendizado, ambos afirmaram que sim. Quando perguntado como era trabalhado o conteúdo em sala de aula de forma expositiva dialogada, recurso áudios visuais, relação conteúdo com o cotidiano dos alunos e questionamento do conteúdo, porém, não se notou exposição de recurso áudios visuais.

Foi perguntado que metodologias novas e atualização são buscadas por eles para melhorar a qualidade das aulas, ou isso é desnecessário afirmaram ser essencial à criação novos mecanismos de ensino e aplicação de novos método. Quanto a qual é a sua relação com a Direção, Coordenação e Supervisor, o professor de História afirmou ser ótimo, mas o de Geografia afirmou ser aceitável. Já em relação professor com os outros professores da escola, afirmaram ser harmoniosa. Quanto à realização de trabalhos de campo com as turmas, ambos responderam que não.

Quanto qual seria a opinião o turno da noite é menos prestigiado que os demais ou os trabalhos desenvolvidos neste horário têm a mesma efetividade que os desenvolvidos durante o dia, o professor de História diverge com o de Geografia, por o primeiro afirma não existe distinção entre os horários de funcionamento da escola, já o segundo afirma a mudança de metodologia. Em relação se a escola mantém alguma relação com a universidade exceto por meio de estagiários, afirmaram que sim. Quando perguntado se eles recebiam muitos estagiários e qual sua relação com eles e se possuíam experiências negativas, afirmaram que não recebiam muitos, tinham uma relação amistosa e não explicitaram ter experiências 
negativas. Já qual o seu conselho para um estágio produtivo, responderam que estudar, aprender, experimentar, prepara-se e evoluir sem medo.

Quanto ao tema que será trabalhado na regência foi proposto pelos professores da escola receptora, no qual este consiste no capitalismo na revolução industrial. Esse tema fará com os alunos tenham noção de como o capitalismo pode ser "fabuloso" e perverso ao mesmo.

Este tema é de extrema importância para nossa sociedade, assim como tambem para os alunos possam fazer uso do conhecimento para transformar o lugar onde vivem ou no mínimo a si mesmo.

\section{Considerações}

Neste trabalho percebeu a alta relevância que o Estágio tem na formação acadêmica e decorrentemente na Práxis, assim como que esses três itens estão inteiramente conectados em que a má execução de um reflete no outro.

Conclui-se ainda que o Estágio executado de forma interdisciplinar torna o futuro docente bem mais preparado para lecionar, e ainda percebi a importância da mutua compartilhamento de conhecimento entre ambas as áreas de conhecimento.

Já referente as pesquisa feita no colégio receptor notou-se que na opinião dos alunos ele oferece condições para o seu desenvolvimento, assim como as relações existentes entre os personagem que atuam diariamente é harmônica. Verifica-se ainda que os professores tem um nível relevante de conceituação entre os alunos.

Nas visitas de observação verificou-se a boa relação de todos os atores da escola (alunos, professores, coordenação e diretora), onde pode ser visualizado nos gráficos o resultado desta harmonia em que todos estão de acordo com os rumos que a escola concerne como melhor caminho.

Percebeu que a turma da regência do projeto interdisciplinar do Estágio IV é jovem e já trás consigo bastante responsabilidade e dedicação, pois, trabalham durante o dia e no horário noturno estudam, outro fato que esta turma apresenta é por certa de $85 \%$ deles estarem na idade adequada para a serie que cursa e mais positivo ainda é o aluno mais velho a idade dele não chega a 20 anos.

RPI Revista de Pesquisa Interdisciplinar, Cajazeiras, v. 1, Ed. Especial, 412 - 429, set/dez. de 2016. 
Um dado positivo é que a maior parte dos alunos vem um futuro no caminho da educação e estes pretendem ingressar no ensino superior, assim como entendem a importância do ensino básico no seu desenvolvimento e construção do seu conhecimento base como formação cidadã.

Outro item que chega entende-se é que a relação do professores e alunos é ótima, assim se nota nos gráficos o nível de aprovação dos professores pelos alunos. Fica nítido que para estes alunos a metodologia do professor vale mais apena do que uma mega infraestrutura sem metodologia adequada a sua realidade.

\section{REFERÊNCIAS}

ANTÔNIO, José. História Do Colégio Comencial De Cajazeiras Disponível em: http://www.obeabadosertao.com.br/v3/jose_antonio/ história do colégio comercial de cajazeiras - confira-as-ultimas-de-cajazeiras._555. html. Acessado em 23 de agosto de 2016.

BARBOSA, Ângela Maria; AMARAL, Telma. A Contribuição Do Estágio Supervisionado Na Formação Do Pedagogo. ANAIS.do IX Congresso Nacional de Educação - EDUCERE, III Encontro Sul Brasileiro de Psicopedagogia, Paraná, 2009.

BATISTA, Aline Maria de Melo. Práxis, Consciência De Práxis E Educação Popular: Algumas Reflexões Sobre Suas Conexões. Educ. e Filos., Uberlândia, v. 21, n. 42, p. 169192, jul./dez. 2007.

BERBEL, Neusi Aparecida Navas. Didática E Práxis. ANAIS da II Jornada De Didática E I Seminário De Pesquisa Do Cemad: Docência Na Educação Superior: Caminhos Para Uma Práxis Transformadora, Londrina, 2013.

CARLOS, Ana Fani Alessandri. O Espaço Urbano: Novos Escritos Sobre A Cidade. São Paulo: FFLCH, 2007. Disponibilizado em: http://www.fflch.usp.br/dg/gesp

CHUEIRI, MARY STELA FERREIRA. Concepções Sobre A Avaliação Escolar. Estudos em Avaliação Educacional, v. 19, n. 39, Minas Gerais, jan./abr. 2008.

DASSOLER, Olmira Bernadete; LIMA, Denise Maria Soares. A Formação E A Profissionalização Docente: Características, Ousadia E Saberes. ANAIS.da IX ANPED SUL, Rio Grande do Sul, 2012.

DOMINGUES, Rosângela Curvo Leite; AMARAL, Eliana el at.Conceito Global: Um Método De Avaliação De Competência Clínica. REVISTA BRASILEIRA DE EDUCAÇÃO MÉDICA, Universidade Estadual de Campinas, São Paulo, Brasil, 2009.

HAMMES, Care Cristiane; LOMBA, Roni Mayer.A Interdisciplinaridade No Estágio Curricular De Geografia Da Universidade Estadual De Mato Grosso Do Sul: Experências E RPI Revista de Pesquisa Interdisciplinar, Cajazeiras, v. 1, Ed. Especial, 412 - 429, set/dez. de 2016. 
Práticas Na Formação Docente. ANAIS.do $10^{\circ}$ Encontro Nacional de Prática de Ensino em Geografia, Porto Alegre, 2009.

HYPOLITTO, Dinéia. Formação Docente Em Tempos De Mudanças. Revista Integração, ano xiv, nº56, pag. $91-95$, jan/mar, 2009.

MILANESI, Irton. Estágio Supervisionado: Concepções E Práticas Em Ambientes Escolares. Educar em Revista, Editora UFPR, n. 46, p. 209-227, Curitiba, Brasil, out./dez. 2012.

NORONHA, Olinda Maria. Praxis E Educação. Revista HISTEDBR Online, n.20, p. 86 - 93, Campinas, dez. 2005 - ISSN: 1676-2584

NUNES, Célia Maria Fernandes. Saberes Docentes E Formação De Professores: Um Breve Panorama Da Pesquisa Brasileira. Educação \& Sociedade, ano XXII, no 74, Rio de Janeiro, Abril/2001.

Oliveira, Adriana Maria Evaristo Martinez de. Normas E Padrões Para Trabalhos Acadêmicos E Científicos Da UNOESTE / Adriana Maria Evaristo Martinez de Oliveira, Jakeline Margaret de Queiroz Ortega, Michele Mologni; Coordenação: Regina Rita Liberati Silingovschi.-- Presidente Prudente: Unoeste - Universidade do Oeste Paulista, 2015.

OLIVEIRA, Adriana; APARECIDA, Celena et al. Avaliação: Conceitos Em Diferentes Olhares, Uma Experiência Vivenciada No Curso De Pedagogia. Curitiba, novembro de 2007.

PENA, Geralda Aparecida de Carvalho. Formação Docente E Aprendizagem Da Docência: Um Olhar Sobre A Educação Profissional. Educação em Perspectiva, v. 2, n. 1, p. 98-118, Viçosa, jan./jun. 2011.

RECHE, Bruna Donato; TUMA, Magda Madalena. Estágio E Interdisciplinaridade: Possibilidades Para A Formação Docente No Estágio Curricular Nos Anos Iniciais Do Ensino Fundamental.Revista Eletrônica Pro-Docência/UEL. Edição No. 4, Vol. 1, Londrina, juldez. 2013. ISSN 2318-0013 - DISPONÍVEL EM: http://www.uel.br/revistas/prodocenciafope. SANTOS, Milton. POR OUTRA GLOBALIZAÇÃO: do pensamento único e universal. São Paulo, 1994.

SARAIVA, Jucier Ricarte; SILVA, Andressa Sarmento da et al. Um olhar descritivo sobre a prática de execução do estágio supervisionado em ensino de geografia I. Universidade Federal da Paraíba, João Pessoa, 2015.

SILVA, José Pedro Guimarães da. Prática Pedagógica Interdisciplinar No Estágio Supervisionado De Um Curso De Licenciatura Em Ciências Biológicas. ANAIS.do IV Colóquio Internacional: "Educação e Contemporaneidade”. São Cristovão, setembro de 2012. 
SILVA, Wagner Rodrigues. Letramento Do Professor Em Formação Inicial:

Interdisciplinaridade No Estágio Supervisionado Da Licenciatura. Pontes Editora, Campinas SP, 2012.

TOZATO, Mariana de Oliveira. O processo avaliativo da equipe multidisciplinar no $3^{\circ}$ ano da rede municipal de ensino de Curitiba. Universidade Federal do Paraná, Curitiba, 2011.

VÁZQUEZ, Adolfo Sanchez. Filosofia Da Práxis. Ed, 2º. Tradução de Luiz F. Cardoso. Rio de Janeiro: Paz e Terra, 1977. 